\title{
RECENT RESULTS ON THE ACCURATE MEASUREMENTS OF THE DIELECTRIC CONSTANT OF SEAWATER AT 1.413GHZ
}

\author{
R. H. Lang*, Y. Tarkocin*, C. Utku**, D. M. Le Vine** \\ *Dept. of Electrical \& Computer Ëngineering, George Washington University \\ Washington, DC 20052 USA - email: lang@gwu.edu \\ **Instrumentation Sciences Branch, Code 614.6, NASA/GSFC \\ Greenbelt, MD 20771 USA
}

\begin{abstract}
Measurements of the complex. dielectric constant of seawater at $30.00 \mathrm{psu}, 35.00 \mathrm{psu}$ and $38.27 \mathrm{psu}$ over the temperature range from $5^{\circ} \mathrm{C}$ to $35^{\circ} \mathrm{C}$ at $1.413 \mathrm{GHz}$ are given and compared with the Klein-Swift results. A resonant cavity technique is used. The calibration constant used in the cavity perturbation formulas is determined experimentally using methanol and ethanediol (ethylene gycol) as reference liquids. Analysis of the data shows that the measurements are accurate to better than $1.0 \%$ in almost all cases studied.
\end{abstract}

Index Terms- Dielectric constant, microwave resonant cavity, salinity, seawater.

\section{INTRODUCTION}

This paper describes continuing measurements of the dielectric constant of seawater at $1.413 \mathrm{GHz}$ by a resonant cavity technique. Details of the physical measurement setup have been discussed in IGARSS 2007 paper [1] and measurements of seawater at 30 psu over a temperature range from $10^{\circ} \mathrm{C}$ to $35^{\circ} \mathrm{C}$ have been presented in the MicroRad Specialist Meeting in March, 2008 [2]. As has been pointed out in [2], the measurement method relies on the perturbation formula

$$
\begin{aligned}
& \varepsilon_{r}^{\prime}-1=2 C \Delta f / f_{o}, \quad \Delta f=f_{o}-f \\
& \varepsilon_{r}^{\prime \prime}=C \Delta(1 / Q), \quad \Delta(1 / Q)=1 / Q-1 / Q_{o}
\end{aligned}
$$

where the complex dielectric constant, $\varepsilon_{r}=\varepsilon_{r}^{\prime}+i \varepsilon_{r}^{\prime \prime}$, is calculated from the frequency shift, $\Delta f$, and the shift in the cavity $Q$ occurring upon the introduction of seawater into the cavity. The measurement method depends on the calibration constant, $C$, which can be obtained from the measurement of a reference liquid with a known dielectric constant. In [2] the calibration constant was calculated using measurements of methanol.
Ho, et al [3] made L-band seawater dielectric measurements using the cavity technique in 1974. Blanch and Aguasca [4] have made measurements of seawater dielectric more recently at this frequency using a waveguide method.

Following these introductory comments, new measurements of the calibration constant using methanol, ethanediol (ethylene glycol) and ethanol will be discussed in section II. In section III, measurements of seawater at 35 and 38 psu are presented along with previously obtained results at 30 psu. Concluding remarks appear in section IV.

\section{CALIBRATION}

In this manuscript, new measurements of the calibration coefficient using several different reference liquids with known dielectric constants will be explored. Four liquids have been considered as candidates. They are: methanol, ethanediol, ethanol and butanol. Accurate dielectric constants for all liquids in the frequency and temperature range of interest can be found in Gregory and Clark [5]. In the past, the calibration coefficient has been obtained using an average of several methanol measurements. Recently, a few more methanol measurements have been made after a time lapse of several months and after several small changes to the measurement setup. These measurements have been incorporated into the average and a new calibration coefficient has been computed. Measurements of ethanediol have also been made and used to obtain a calibration constant. The two other liquids, butanol and ethanol, have not been chosen as a reference liquids due to their smaller

TABLE I

DIELECTRIC CONSTANTS OF REFERENCE LIQUIDS

\begin{tabular}{|c|c|c|}
\hline $\begin{array}{l}\text { Liquid } \\
\text { Methanol }\end{array}$ & $\begin{array}{l}\text { Real } \\
27.98\end{array}$ & Imag. \\
\hline Ethanediol & 20.13 & 16.97 \\
\hline Ethan & 10.00 & 9.10 \\
\hline Butanoi & 3.99 & 2.77 \\
\hline
\end{tabular}
AT $1.4 \mathrm{GHz}$ AND $20^{\circ} \mathrm{C}$ 


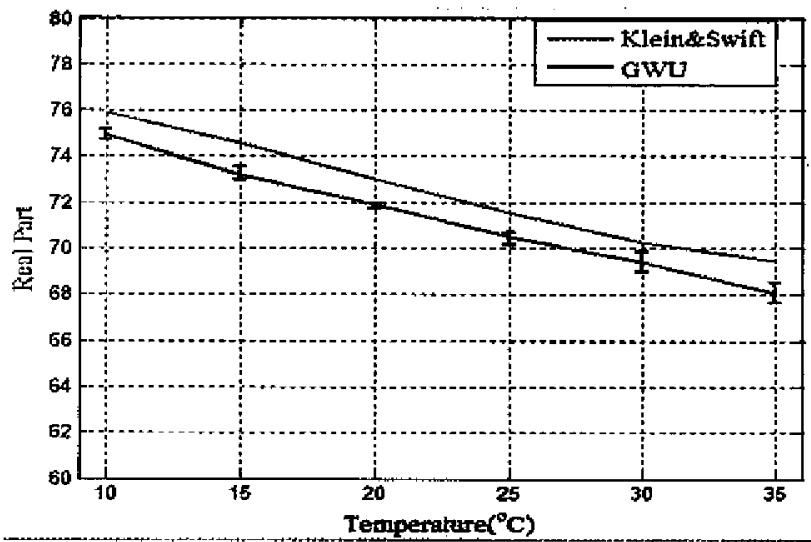

Fig. 1. Comparison of the real part of the dielectric constant of 30.00 psu seawater obtained in this study (GWU) with the KleinSwift model.

dielectric constant values compared to the dielectric constants of methanol and ethanediol.

In Table I, the real and imaginary parts of the dielectric constants at $1.4 \mathrm{GHz}$ and $20^{\circ} \mathrm{C}$ for the four reference liquids are shown. The results have been obtained by a linear interpolation of the data give in [5] at 1.0 and $1.5 \mathrm{GHz}$. An examination of the table shows that butanol and ethanol have much lower dielectric values than the other two reference liquids. A smaller dielectric constant value causes a smaller resonant frequency shift and quality factor change. Thus, the $\mathrm{C}$ constant value becomes more dependent on resonant frequency and quality factor fluctuations. For example, a frequency shift of $24 \mathrm{KHz}$ occurs when methanol is introduced into the cavity while only a $7.5 \mathrm{KHz}$ shift occurs for ethanol. A fluctuation of $100 \mathrm{~Hz}$ variation in resonant frequency shift leads to a 0.42 $\%$ change in the $\mathrm{C}$ constant calculation in the case of methanol, and $1.34 \%$ change in the case of ethanol.

\subsection{Methanol}

The experimental data for the methanol calibration measure-

TABLE II

METHANOL EXPERIMENT DATA

\begin{tabular}{|c|c|c|c|c|c|c|c|}
\hline $\begin{array}{l}\text { Test } \\
\text { Number }\end{array}$ & Date & $\begin{array}{l}\text { Empty: } \\
\text { fo(Hz) }\end{array}$ & $\begin{array}{l}\text { Methanol } \\
\text { f(Hz) }\end{array}$ & $\begin{array}{c}\Delta / \\
(\mathrm{Hz})\end{array}$ & $Q_{0}$ & $\begin{array}{c}\text { Iethanol } \\
Q\end{array}$ & \\
\hline 1 & $\operatorname{Jan}, 26$ & $1,413,279,0003$ & $1,413,255,084$ & 23.919 & 7,739 & 6.976 & $1.41 \mathrm{E}-$ \\
\hline 2 & Jan, 26 & $1,413,278$ & 9,413 & 24,393 & 7,7 & 6,980 & \\
\hline 3 & $\operatorname{Jan}, 27$ & $1,413,2$ & 1,413 & 24,054 & 7.7 & 7,004 & 1.4 \\
\hline 4 & Jan , 31 & $1,413,2$ & 1.413 & 24,400 & 7,692 & 6,938 & $1.41 \mathrm{E}-\mathrm{D}$ \\
\hline 5 & Feb,1 & 1,413 & 1,413 & 24,366 & 7,675 & 6,922 & 1.4 \\
\hline 6 & Feb, & 1,413 & $1,413,2$ & 24,218 & 7,8 & 6.89 & 1.3 \\
\hline 7 & May, 13 & 1,41 & $1,413,1$ & 23,899 & 78 & 7,068 & $1.40 \mathrm{E}-\mathrm{D}$ \\
\hline \multirow[t]{3}{*}{ B } & May, 14 & $1,413,205,702$ & $0,413,181$ & 23,870 & 7,852 & 7.074 & $1.40 \mathrm{E}$ \\
\hline & Average & $1,413,253,830$ & $1,413.229$ & 24,140 & 7,746 & 6,983 & $1.41 E-$ \\
\hline & $\begin{array}{c}\text { Stder } \\
\text { Etror[\%) }\end{array}$ & & & $\begin{array}{l}232 \\
0.96\end{array}$ & & & $\begin{array}{c}1.19 E-07 \\
0.84\end{array}$ \\
\hline
\end{tabular}

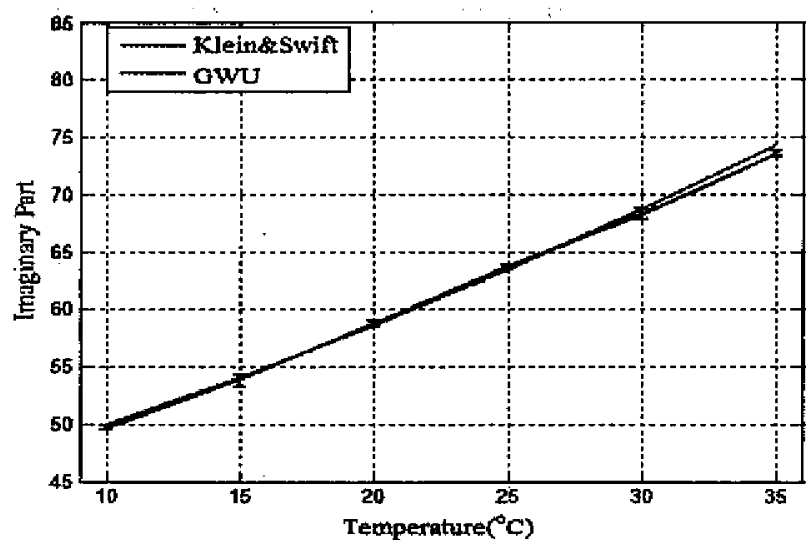

Fig. 2. Comparison of the imaginary part of the dielectric constant of 30.00 psu seawater obtained in this study (GWU) with the Klein-Swift model

-ments is shown in Table II. In this table appear the six measurements given in [2] plus two recent measurements. An examination of the table shows that the frequency shift and the change in the $Q$ do not change very much between the old and the new measurements. The average calibration coefficient using the 6 old measurements is $786 \times 10^{3}$ while the average value of $\mathrm{C}$ with the new measurements included is $790 \times 10^{3}$. A change of approximately $0.5 \%$.

\subsection{Ethanediol}

Ethanediol was chosen as a second calibration liquid because of its comparatively high dielectric value. Four experiments were conducted, and their average results are shown in Table III. The ethanediol experiment results have a greater variance than methanol measurements. This may be attributed to the fact that ethanediol is more viscous and has a natural susceptibility to combine with water.

The calibration coefficient was evaluated using the data given in table III for ethanediol at $20^{\circ} \mathrm{C}$. The calibration coefficient obtained using the average value of the frequency shift given in Table III was found to be $794 \times 10^{3}$. This calibration constant value is $0.47 \%$ greater than the one obtained by using methanol.

TABLE III

ETHYLENE GLYCOL EXPERIMENT DATA

\begin{tabular}{|c|c|c|c|c|c|c|c|}
\hline $\begin{array}{l}\text { Test } \\
\text { Number }\end{array}$ & Date & $\begin{array}{l}\text { Emply } \\
\text { fo(Hifr) }\end{array}$ & $\begin{array}{c}\text { E.Chycol } \\
\text { (Hitz) }\end{array}$ & $\stackrel{\Delta f}{(H z)}$ & $\begin{array}{c}\text { Empty } \\
Q_{0}\end{array}$ & $\begin{array}{c}\text { E.Gycol } \\
Q\end{array}$ & \\
\hline 1 & Jun ,9 & $1,413,189,194$ & $1,413,172,070$ & 17.124 & 7,822 & 6.724 & 2.09E-05 \\
\hline 2 & Jun ,9 & $1,413,190,456$ & $1,413,1$ & 17,240 & 7,817 & 6.691 & 6 \\
\hline 3 & Jun ,12 & & & 16,660 & 7,82 & 6,723 & 2.09 \\
\hline \multirow[t]{3}{*}{4} & Jun ,13 & 1,413 & $1,413,168,934$ & 17,143 & 7.836 & 6,699 & $2.17 \mathrm{E}-05$ \\
\hline & $\begin{array}{c}\text { Average } \\
\text { Stdev }\end{array}$ & $1,413,187,734$ & $1,413,170,692$ & $\begin{array}{c}77,042 \\
259\end{array}$ & 7,825 & 6,709 & $\begin{array}{l}2.12 E-05 \\
4.08 E-07\end{array}$ \\
\hline & Error(t) & & & 1.52 & & & 1.92 \\
\hline
\end{tabular}




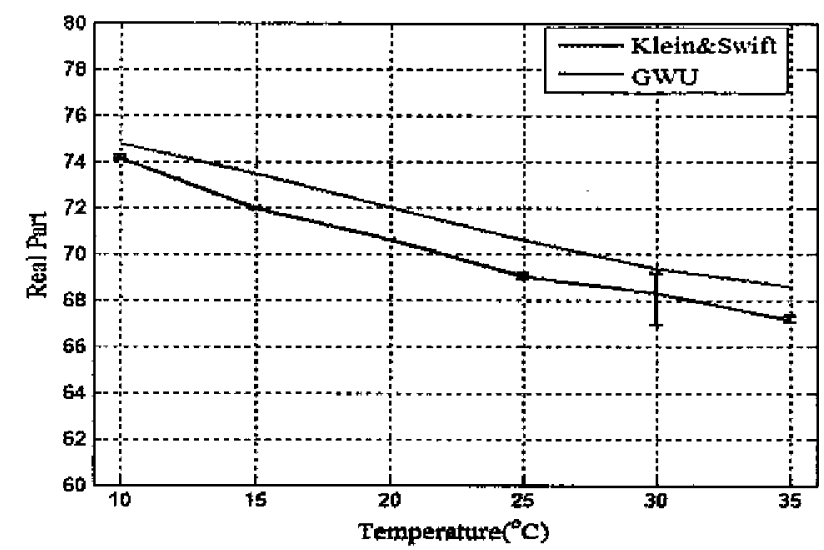

Fig. 3. Comparison of the real part of the dielectric constant of 35.00 psu seawater obtained in this study (GWU) with the KleinSwift model.

\section{DATA}

The complex dielectric constant measurements of seawater at $30.00,35.00$ and 38.27 psu over the temperature range from $10^{\circ} \mathrm{C}$ to $35^{\circ} \mathrm{C}$ in increments of $5.0^{\circ} \mathrm{C}$ are given in Figs. 1-6. Several measurements have been conducted at each temperature and salinity value to observe the repeatability of the results. The data has been calibrated using the new methanol calibration constant of $790 \times 10^{3}$.

The 30.00 psu measurements which were shown in recent MicroRad specialist meeting [2] are reevaluated by using the new calibration constant. Since the old and new calibration coefficients differ by only $0.5 \%$, the new data for $30.00 \mathrm{psu}$ is very close the results presented in [2]. The average dielectric constant of three experiments at each temperature value with error bars for real and imaginary parts are plotted in Figs. 1 and 2 respectively. As can be seen from the figures, the GWU $30.00 \mathrm{psu}$ dielectric constant results for the real part are lower than Klein and Swift [6] results by $1.3 \%-2.1 \%$ while the imaginary values

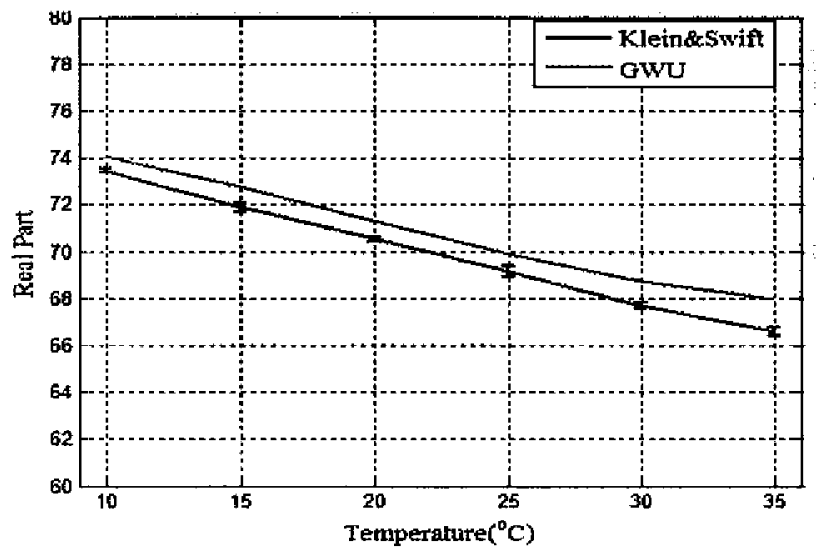

Fig. 5. Comparison of the real part of the dielectric constant of 38.27 psu seawater obtained in this study (GWU) with the KleinSwift model

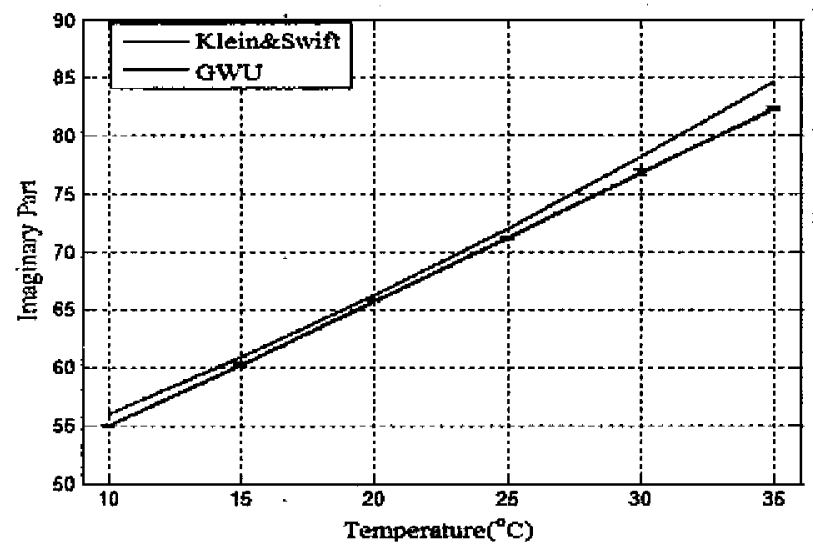

Fig. 4. Comparison of the imaginary part of the dielectric constant of $35.00 \mathrm{psu}$ seawater obtained in this study (GWU) with the Klein-Swift model.

are closer with a maximum difference being less than $1.2 \%$.

Two different measurements have been concucted for each temperature at $35.00 \mathrm{psu}$ and $38.27 \mathrm{psu}$. The average dielectric constant results with error bars for real and imaginary parts are plotted in Figs. 3-6 at these salinity values. The results have similar trends at 35.00 and 38.27 psu compared to Klein and Swift results. The GWU real part results are lower than Klein and Swift by $0.9 \%-2.2 \%$ at $35.00 \mathrm{psu}$, and by $0.8 \%-2.1 \%$ at $38.27 \mathrm{psu}$. Similarly, the GWU imaginary part results are lower than Klein and Swift by $0.8 \%-2.9 \%$ at $35.00 \mathrm{psu}$, and by $1.2 \%-3.2 \%$ at 38.27 psu. From Fig. 3 it is seen that there exists an anomalously large variance for the measurements of the real part at $30^{\circ} \mathrm{C}$. There is no explanation for this behavior at this time but more measurements will be conducted at temperatures close to $30^{\circ} \mathrm{C}$ for seawater with a psu of 35 .

The effect of the variability of the calibration coefficient is shown in Figs. 7-8. Since the calibration coefficient for methanol has a variability of about $1 \%$, the curves for seawater with a psu of 30.00 appearing in Figs 1-

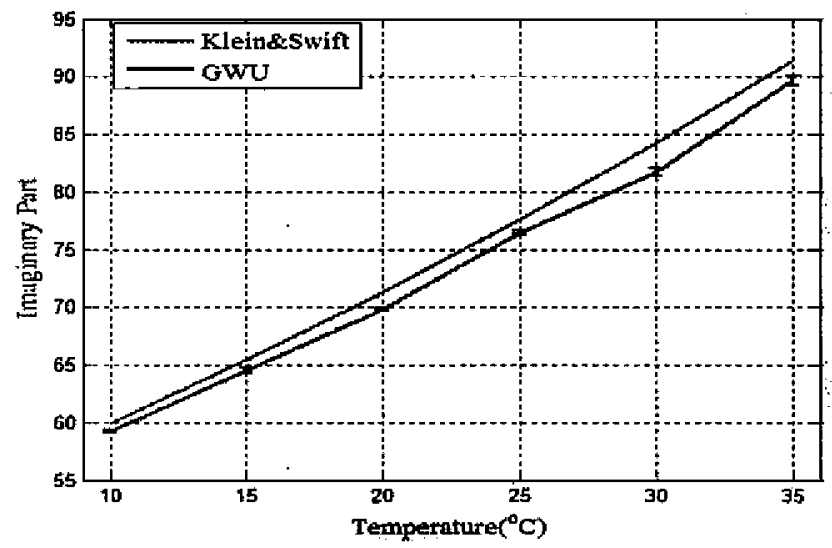


Fig 6. Comparison of the imaginary part of the dielectric constant of 38.27 psu seawater obtained in this study (GWU) with the Klein-Swift model

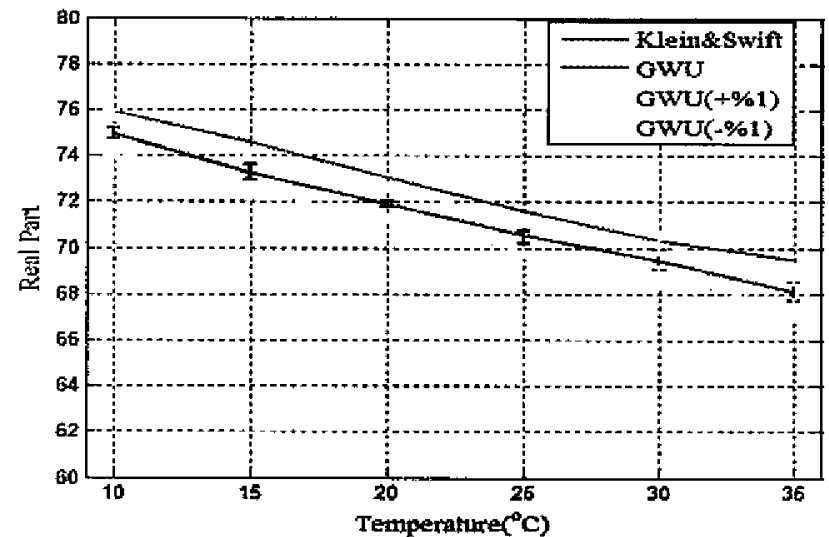

Fig 7. Comparison of the real part of the dielectric constant of 30.00 psu seawater obtained in this study (GWU) with the KleinSwift model by considering $\% 1$ change in the calibration constant value.

2 have been shifted up and down by this amount. It is seen that even with this variability taken into account, the measurements of the real part of the dielectric constant are still below the Kline Swift results.

\section{CONCLUSIONS}

In this paper, the complex dielectric constant of the seawater at $30.00 \mathrm{psu}, 35.00 \mathrm{psu}$ and $38.27 \mathrm{psu}$ has been measured at temperatures from $10^{\circ} \mathrm{C}$ to $35^{\circ} \mathrm{C}$ in increments of $5^{\circ} \mathrm{C}$ by using a temperature controlled resonant cavity. The experiments at each temperature have been repeated three times for $30.00 \mathrm{psu}$, and two times for other salinity values to indicate the fluctuations in measurement data. Methanol has been used as a reference liquid. Repeated measurements of methanol have produced an average calibration constant with fluctuations of less than $1.0 \%$.

Comparison of the measurement results with Klein and Swift has shown that the real part is generally $2 \%$ lower than the value predicted by Klein and Swift while the imaginary part is in better agreement.

Finally, four different reference liquids were considered. Those with lower dielectric values were eliminated for accuracy considerations while ethanediol exhibited some unusual behavior which is still being investigated.

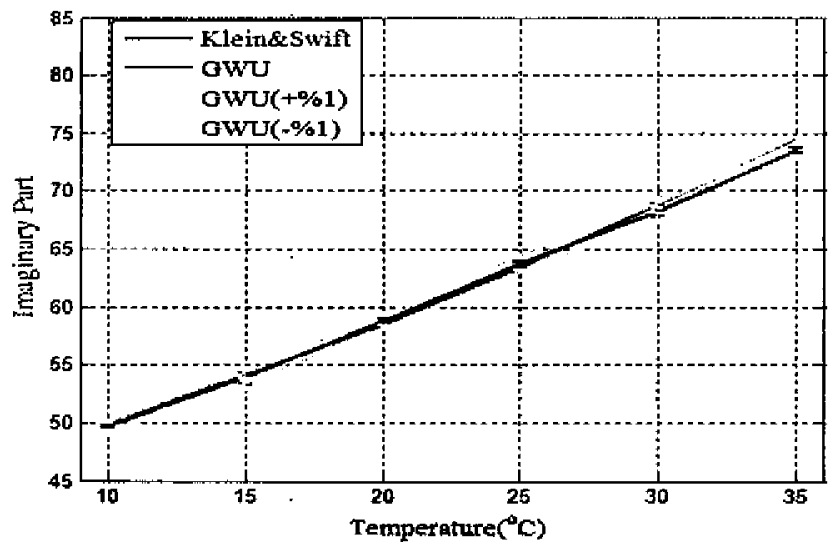

Fig 8. Comparison of the imaginary part of the dielectric constant of 30.00 psu seawater obtained in this study (GWU) with the Klein-Swift model by considering $\% 1$ change in the calibration constant value.

\section{REFERENCES}

[1] R.Lang, C. Utku, Y. Tarkocin, J. Janizcek, D. M. Levine" Accurate L-Band Measurements of the Dielectric Constant of Seawater", IEEE International Geoscience and Remote Sensing Symposium, Barcelona/Spain, July 2007

[2] R.Lang, Y. Tarkocin, , C. Utku, D. M. Levine " Accurate LBand Dielectric Constant Measurements of Seawater", 10th Specialist Meeting on Microwave Radiometry and Remote Sensing of the Environment (MICRORAD ), Florence /Italy, March,2008.

[3] W. Ho, W. Love and M.J. van Melle, "Measurements of the dielectric properties of sea water at $1.43 \mathrm{GHz}$," NASA Contractor Report CR-2458, 1974.

[4] S.Blanch and A.Aguasca, "Dielectric permittivity measurements of seawater," Proc. of the ESA Euro STARRS, WISE and LOSAC CampaignWorkshop, ESA-SP25, 2003.

[5] A.P.Gregory, R.N.Clarke, "Tables of the complex permittivity of dielectric reference liquids at frequencies up to $5 \mathrm{GHz}$," Nat. Phys. Lab. report CETM 33, U.K., September 2001

[6] L.A.Klein and C.T.Swift, "An improved model for the dielectric constant of sea water at microwave frequencies," IEEE Trans. Antennas Propagat., vol. AP-25, no. 1, January 1977. 